\title{
Changes in the plasma aminogram of parenterally fed infants treated with dexamethasone for bronchopulmonary dysplasia
}

\author{
P C Ng, K G Brownlee, E J Kelly, M J Henderson, M Smith, P R F Dear
}

\begin{abstract}
A substantial increase in the plasma concentration of most amino acids was observed in 59 preterm infants with chronic lung disease soon after the initiation of dexamethasone therapy. The size of increase appeared to be dose related. This phenomenon is likely to be the result of steroid induced protein catabolism. Interestingly, neither phenylalanine nor tyrosine concentrations were significantly increased.
\end{abstract}

(Arch Dis Child 1992;67:1193-5)

Dexamethosone is now often used in the treatment of bronchopulmonary dysplasia (BPD). ${ }^{1-4}$ Corticosteroid therapy is associated with many serious complications which have yet to be thoroughly and systematically examined in preterm infants. Since the decision to prescribe dexamethasone will depend on the clinician's perception of the risks and benefits of the treatment, there is an urgent need to establish and to document any undesirable effects as accurately and comprehensively as possible.

An important side effect of corticosteroids is an increase in resting metabolic expenditure and urinary nitrogen loss due to promotion of protein catabolism. ${ }^{5-7}$ We have previously reported a marked rise in blood urea concentration in dexamethasone treated babies secondary to structural protein breakdown. ${ }^{8}$ As the breakdown of protein releases amino acids, one aspect of this effect of steroids might be to cause hyperaminoacidaemia, especially in babies already receiving an amino acid solution parenterally. In view of the potentially toxic effect of some amino acids, notably, but not exclusively, phenylalanine, we monitored the plasma aminogram in parenterally fed preterm infants before and during dexamethasone treatment for BPD.

\section{Patients and methods}

Over a four year period between January 1987 and December 1990, 59 parenterally fed preterm infants who received dexamethasone for BPD were studied. Their clinical characteristics and the severity of their chronic lung disease, as reflected by the duration of intermittent positive pressure ventilation and oxygen dependency, are summarised in table 1 .

Steroids were started at a mean (SD) postnatal age of 20 (9) days. In all cases, a three
Table 1 The clinical characteristics of the 59 babies

\begin{tabular}{lc}
\hline Clinical characteristics & Mean (SD) \\
\hline Gestational age (weeks) & $27(2)$ \\
Birth weight (g) & $1026(298)$ \\
Postnatal age when dexamethasone started (days) & $20(9)$ \\
No of days on assisted ventilation & $26(13)$ \\
No of days dependent on supplementary oxygen & $57(320$ \\
No of days in hospital & $102(43)$ \\
\hline
\end{tabular}

week course of dexamethasone was given, starting at $0.6 \mathrm{mg} / \mathrm{kg} /$ day, reducing to 0.3 $\mathrm{mg} / \mathrm{kg} /$ day in the second week and to $0 \cdot 15$ $\mathrm{mg} / \mathrm{kg} /$ day in the third week. All babies who entered the trial were on total parenteral nutrition. The regimen of the unit was to start all ventilated preterm babies on parenteral nutrition on the second day of life with $0.5 \mathrm{~g} / \mathrm{kg} /$ day of Vamin 9 glucose, $0.5 \mathrm{~g} / \mathrm{kg} /$ day of Intralipid $20 \%$ (KabiVitrum) and $10 \%$ dextrose, plus electrolytes, trace minerals, and vitamins. In the absence of contraindications such as severe jaundice, metabolic acidosis or sepsis, amino acid and fat intakes were increased daily by increments of $0.5 \mathrm{~g} / \mathrm{kg}$, to a maximum of 3 and $3.5 \mathrm{~g} / \mathrm{kg} /$ day of amino acid and lipid respectively. All nutrients were infused at a constant rate throughout the 24 hour period. Daily fluid intake was increased according to estimated fluid requirements and carbohydrate tolerance, usually reaching the maximum level of 180 $\mathrm{ml} / \mathrm{kg} /$ day on day 7 . Thereafter, these rates of fluid and nutrient intake were maintained throughout the whole study period (one week before and during the three weeks of steroid treatment) to ensure constant protein and energy intake until mechanical ventilatory support was discontinued and the baby was well enough to tolerate enteral milk feeds.

Plasma aminograms were checked at weekly intervals as long as the babies were on parental nutrition. Amino acid analysis was carried out on a Hilger Chromaspeck automated ion exchange amino acid analyser. The chemical pathology laboratory participated in the external quality control system (NEQUAS) operated by the Wolfson Research Laboratory, Queen Elizabeth Medical Centre, Birmingham.

Statistical comparisons between sets of parametric data were performed using the Student's paired $t$ test.

\section{Results}

The concentrations of 19 amino acids were measured. There were no significant differences between the pretreatment (week -1) concentrations and our previously published 
Table 2 Mean plasma amino acids concentrations before dexamethasone treatment and mean change from base measurements during study ( $\mathrm{mmol} /$ )

\begin{tabular}{lcccc}
\hline Amio acid & $\begin{array}{l}\text { Week-1 } \\
\text { Mean (SE) }\end{array}$ & $\begin{array}{l}\text { Week 1 } \\
\text { Change (SE) }\end{array}$ & $\begin{array}{c}\text { Week 2 } \\
\text { Change (SE) }\end{array}$ & $\begin{array}{l}\text { Week 3 } \\
\text { Change (SE) }\end{array}$ \\
\hline Aspaartic acid & $61(4)$ & $+21(5)^{* *}$ & $+12(6)$ & $+7(10)$ \\
Threonine & $207(13)$ & $+66(18)^{* *}$ & $-24(21)$ & $-38(18)$ \\
Serine & $325(17)$ & $+178(26)^{* *}$ & $+93(36)^{*}$ & $+51(25$ \\
Glutamic acid & $233(14)$ & $+87(19)^{* *}$ & $+53(23)^{*}$ & $-4(30)$ \\
Glutamine & $518(25)$ & $+367(42)^{* *}$ & $+230(32)^{* *}$ & $+348(33)^{* *}$ \\
Glycine & $359(14)$ & $+163(24)^{* *}$ & $+54(26)^{*}$ & $+41(21)$ \\
Alanine & $280(14)$ & $+263(30)^{* *}$ & $+221(24)^{* *}$ & $+163(33)^{*}$ \\
Cystine & $48(3)$ & $+18(5)^{* *}$ & $+11(4)^{*}$ & $+6(5)$ \\
Valine & $219(8)$ & $+68(11)^{* *}$ & $+35(13)^{*}$ & $+20(15)$ \\
Methionine & $31(2)$ & $+24(3)^{* *}$ & $+12(3)^{* *}$ & $+10(3)^{*}$ \\
Isoleucine & $64(4)$ & $+25(4)^{* *}$ & $+16(6)^{* *}$ & $+22(8)^{*}$ \\
Leucine & $103(4)$ & $+42(6)^{* *}$ & $+29(7)^{* *}$ & $+25(8)^{*}$ \\
Tyrosine & $330(58)$ & $-29(68)$ & $-176(69)^{*}$ & $-198(95)^{*}$ \\
Phenylalanine & $174(11)$ & $+22(14)$ & $-44(16)^{*}$ & $-51(21)^{*}$ \\
Histidine & $102(3)$ & $+34(6)^{* *}$ & $+23(5)^{* *}$ & $+8(5)$ \\
Ornithine & $212(12)$ & $+112(12)^{* *}$ & $+66(12)^{* *}$ & $+28(11)^{*}$ \\
Lysine & $157(11)$ & $+132(15)^{* *}$ & $+82(16)^{* *}$ & $+29(20)$ \\
Arginine & $21(2)$ & $+24(5)^{* *}$ & $+19(5)^{* *}$ & $-2(4)$ \\
Proline & $376(24)$ & $+207(28)^{* *}$ & $+15(32)$ & $-54(33)$ \\
\hline Signican & & & & \\
\hline
\end{tabular}

Significant change ${ }^{*} \mathrm{p}<0.05 ; * * \mathrm{p}<0.01$.

reference data. ${ }^{9}$ Table 2 documents the change in plasma amino acid concentrations during the full study period from week -1 to week 3.

When the pretreatment plasma amino acid concentrations were compared with those in the first week of treatment, all except the aromatic amino acids, phenylalanine and tyrosine, showed a significant increase in concentration $(p<0.01)$. During the second week of treatment, at half of the initial dexamethasone dose, most amino acid concentrations continued to be significantly raised $(p<0.05)$. Three, however, returned to their pretreatment concentrations and they were aspartic acid, threonine, and proline. In the final week of steroid treatment, at a quarter of the original dose, most amino acid concentrations returned to their pretreatment concentration. Only glutamine, alanine, methionine, isoleucine, leucine, and ornithine concentrations were still significantly raised $(p<0 \cdot 05)$. Both the amino acids in the aromatic group showed a significant decrease in plasma concentration at week 3 .

The overall percentage increase of the total plasma amino acid concentrations from the pretreatment value for weeks 1,2 , and 3 were $45 \%, 17 \%$, and $5 \%$ respectively.

\section{Discussion}

Dexamethasone belongs to the catabolic class of steroids and therapeutic doses of such drugs are known to induce hypermetabolism. They cause lipolysis and proteolysis, ${ }^{10}$ enhance gluconeogenesis, and interfere with peripheral glucose uptake and utilisation. ${ }^{10}$ We have recently reported enhanced protein catabolism in preterm infants given dexamethasone for the treatment of bronchopulmonary dysplasia. ${ }^{8}$ We speculated that if structural proteins in the nervous system were involved, neurodevelopmental outcome might be prejudiced. As one of the complications of total parenteral nutrition in the newborn is an increase of plasma amino acid concentrations, ${ }^{11-14}$ the amino acids released as a consequence of steroid induced structural protein breakdown in this group of infants could aggravate the risk of hyperaminoaci- daemia and represent an additional threat to the integrity of the developing brain.

In this study, we have demonstrated a generalised and substantial increase in plasma concentration of almost all amino acids soon after starting dexamethasone therapy which is the result of steroid induced proteolysis. This effect appears to be dose related, and with the smallest dose of dexamethasone $(0.15$ $\mathrm{mg} / \mathrm{kg} /$ day) in week 3, the majority of plasma amino acid concentrations have returned to their pretreatment values. The overall percentage increase in plasma concentration above the pretreatment value declined from $45 \%$ in the first week, to $17 \%$ in the second week, and to $5 \%$ in the third week. This dose related phenomenon has been well documented in renal transplant patients treated with corticosteroids. $^{715}$ It is, therefore, desirable to use the minimum dose of steroid compatible with effective anti-inflammatory action and to encourage a rapid tapering schedule to minimise the side effect of the treatment.

A possible alternative explanation for the fall in amino acid concentrations in weeks 2 and 3 is that the increased plasma amino acid concentrations of week 1 stimulate increased insulin production. ${ }^{16}$ Insulin, which is well known to have an anabolic effect, could then lead to increased amino acid uptake by the tissues. Leucine, in particular, is known to exert an anabolic effect via increased insulin production. ${ }^{17}$

The largest and most sustained increases in concentration were seen for glutamine and alanine (figs A, B). This is consistent with an enhanced rate of protein catabolism and a subsequent increase in the rate of amino acid catabolism. Amino acids cannot be stored and those liberated by enhanced protein hydrolysis must be catabolised. The first step in the catabolism of all amino acids is a transamination reaction to $\alpha$ ketoglutarate or pyruvate yielding glutamate or alanine. Thus, when there is an enhanced flux of amino acids through the degradative pathways, one would expect to observe an increase in the concentration of the transamination intermediates alanine, glutamine, and glutamic acid.

An increased concentration of certain amino acids may have potential ill effects. In recent years, a series of correspondence in the Lancet ${ }^{11-14}$ reported high plasma phenylalanine concentration in newborn infants on total parenteral nutrition exceeding the toxic limit of $600 \mathrm{mmol} / \mathrm{l}$ recommended for the treatment of phenylketonuria. ${ }^{18} \mathrm{We}$ were both surprised and reassured to find that neither phenylalanine nor tyrosine plasma concentrations increased significantly at any time during dexamethasone treatment. In fact the concentration of both aromatic amino acids decreased significantly in the final week of treatment when compared with their pretreatment control values (figs C, D). Moreover, we did not observe a single instance of either amino acid exceeding the toxic limit during the treatment period. The reason why this group of amino acids behaves differently from the others is uncertain. It may relate to the ability 

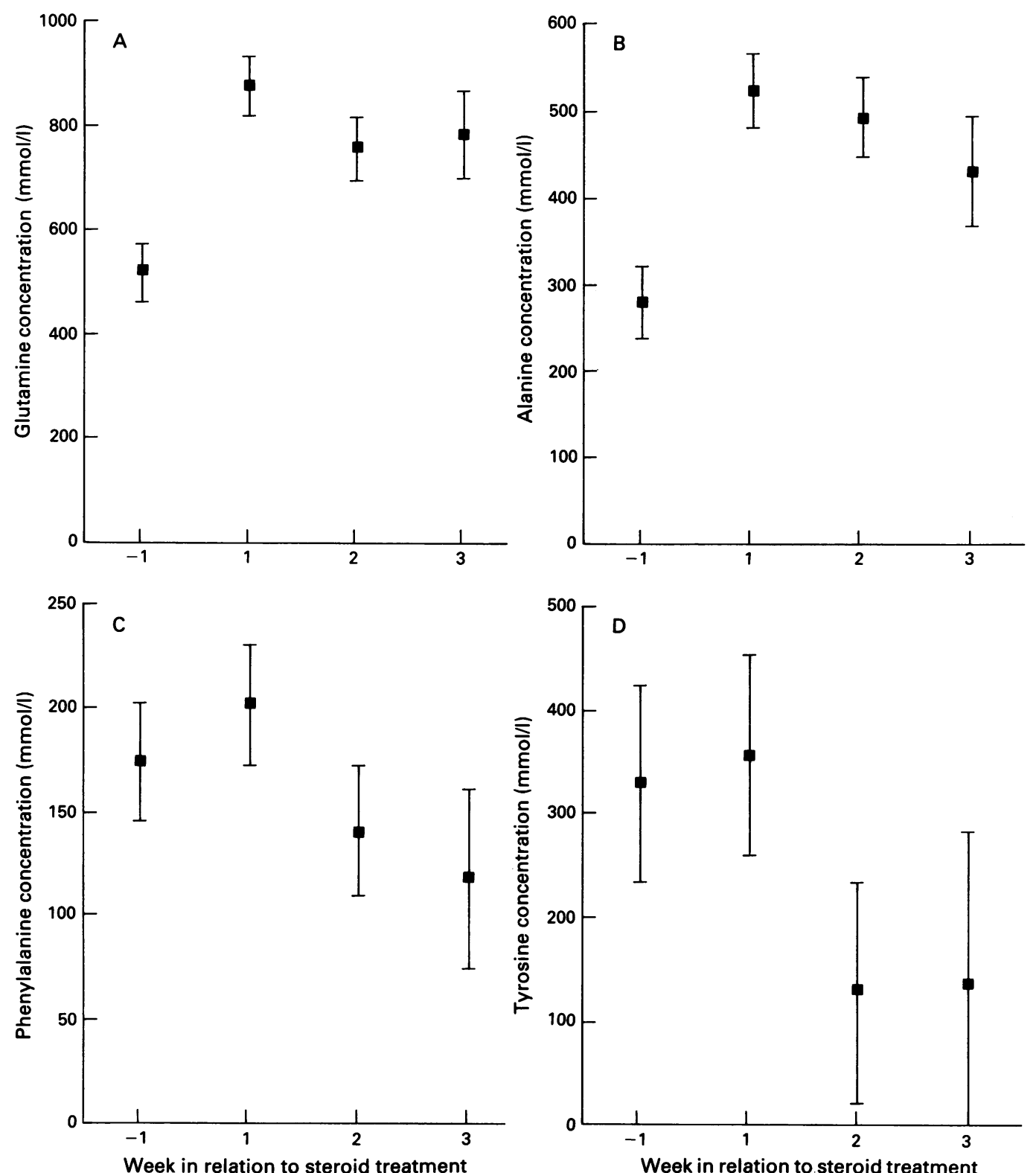

Plasma concentrations before and during dexamethasone treatment (bars show $95 \%$ confidence intervals). (A) glutamine, (B) alanine, (C) phenylalanine, and (D) tyrosine.

of corticosteroids to stimulate the enzymatic activity of specific hepatic aminotransferase ${ }^{10}$ and potentiate the removal of these amino acids from the circulation.

1 Cummings JJ, D'Eugenio DB, Gross SJ. A controlled trial of dexamethasone in preterm infants at high risk for bronchopulmonary dysplasia. N Engl F Med 1989;320:1505-10.

2 Harkavy KL, Scanlon JW, Choudhry PK, Crylack LJ. Dexamethasone therapy for chronic lung disease in ventilator and oxygen-dependent infants: a controlled trial. f Pediatr 1989;115:979-83.

3 Kazzi NJ, Brans YW, Poland RL. Dexamethasone effects on the hospital course of infants with bronchopulmonary dysplasia who are dependent on artificial ventilation. dysplasia who are depend

4 Collaborative Dexamethasone Trial Group. Dexamethasone therapy in neonatal chronic lung disease: an international

placebo-controlled trial. Pediatrics 1991;88:421-7.
5 Greenblatt SH, Long CL, Blakemore WS, Dennis RS, Rayport M, Greiger JW. Catabolic effect of dexamethaRayport M, Greiger JW. Catabolic effect of dexametha-
sone in patients with major head injuries. fournal of sone in patients with major head injuries. Fou

6 Deutschman CS, Konstantinides FN, Raup S, Cerra FB. Physiological and metabolic response to isolated closedhead injury. $\mathcal{F}$ Neurosurg $1987 ; 66: 388-95$

7 Hoy WE, Sargent J A, Fruman RB, Pabico RC, McKenna $\mathrm{BA}$, Starling WA. The influence of glucocorticoid dose on protein catabolism after renal transplantation. $\mathrm{Am} \mathrm{f}$ Med Sci 1986;291:241-7.
8 Brownlee KG, Ng PC, Henderson MJ, Smith M, Green $\mathrm{JH}$, Dear PRF. The catabolic effect of dexamethasone in JH, Dear PRF. The catabolic effect of dexam

9 Clark D, Henderson M, Smith M, Dear PRF. Plasma amino acid concentrations in parenterally fed preterm infants. Arch Dis Child 1989;64:939-42.

10 Yates FE, March DJ. Maran JW. The adrenal cortex. In: Mountcastle VB, ed. Medical physiology. Vol 2. 14th Ed. Chicago: CV Mosby Company, 1980:1 158-601.

11 Bjorkman $\mathrm{O}$, Lindholm $\mathrm{M}$. Phenylalanine content and total parenteral nutrition. Lancet 1987;i:1311.

12 Puntis JWL, Edwards MA, Green A, Morgan I, Booth IW, Ball PA. Hyperphenylalaninaemia in parenterally fed newborn babies. Lancet 1986;i:1105-6.

13 Walker V, Hall MA, Bulusu S, Allan A. Hyperphenylalaninaemia in parenterally fed newborn babies. Lancet 1986;i: 1284 .

14 Evans SJ, Wynne-Williams TCJE, Russel CA, Fairbrother A. Hyperphenylalaninaemia in parenterally fed preterm A. Hyperphenylalaninaemia in parenterally fed preterm
babies. Lancet 1986;ii:1405-6.

15 Seagreaves A, Moore EE, Moore FA, Weil R. Net protein catabolic rate after kidney transplantation: impact of corcatabolic rate after kidney transplantation: impact of corticosteroid immunosuppression.

16 Fajans SS. Floyd JC Jnr, Knopf PF, Conn JW. Effect of amino acids and proteins on insulin secretion in man. Recent Prog Horm Res 1967;23:617-56.

17 Lambert AE, Kanazawa Y, Orci L, Burr IM, Christensen $\mathrm{HN}$, Reynold AE. Stimulation of insulin release in vitro by nonmetabolized amino acid analogues. Proc Soc Exp Biol Med 1971;137:377-81.

18 Scriver CR, Kaufman S, Woo SLC. Phenylketonuria. In: Scriver CR, et al, eds. The metabolic basis of inherited disease. New York: McGraw Hill, 1989:517-20. 